\title{
Osteoblastic adherence regulates hematopoietic stem cell self- renewal and differentiation: a conceptional in vitro and in vivo study
}

\author{
Teruyuki Kajiume $^{1,2}$, Yumi Kawahara ${ }^{3}$, Louis Yuge ${ }^{3}$, Masao Kobayashi ${ }^{2,4}$ \\ ${ }^{1}$ Mukainada Child Clinic, Hiroshima, Japan; ${ }^{2}$ Department of Pediatrics, Graduate School of Biomedical Sciences, Hiroshima University, Hiroshima, \\ Japan; ${ }^{3}$ Division of Bio-Environmental Adaptation Sciences, Graduate School of Health Sciences, Hiroshima University, Hiroshima, Japan; ${ }^{4}$ Japanese \\ Red Cross Chugoku-Shikoku Block Blood Center, Hiroshima, Japan \\ Contributions: (I) Conception and design: T Kajiume; (II) Administrative support: Y Kawahara; (III) Provision of study materials or patients: T \\ Kajiume, Y Kawahara; (IV) Collection and assembly of data: T Kajiume; (V) Data analysis and interpretation: T Kajiume, Y Kawahara, L Yuge; (VI) \\ Manuscript writing: All authors; (VII) Final approval of manuscript: All authors. \\ Correspondence to: Teruyuki Kajiume, MD, PhD. Mukainada Child Clinic, 24-26 Aosaki-naka, Fuchu-cho, Aki-gun, Hiroshima 735-0016, Japan. \\ Email: kajiume@mndcc.jp.
}

\begin{abstract}
Background: Intrinsic factors related to self-renewal regulatory factors in hematopoietic stem cells are well known; however, limited information is available on extrinsic factors, such as the cell environment. Therefore, in this study, we analyzed the regulatory mechanism of hematopoietic stem cell selfrenewal, focusing on the osteoblastic niche, and examined how adherence to osteoblasts affects stem cell differentiation.
\end{abstract}

Methods: For this experimental study, we developed a co-culture system for hematopoietic stem cells and osteoblasts, such that cells adhered to osteoblasts can be separated from those that do not. Murine Sca1positive cells were separated into groups according to whether they were attached to osteoblasts or detached from osteoblasts, and each group was then subjected to colony assays and bone marrow transplantation experiments.

Results: Adhered Sca1-positive cells developed more secondary colonies than non-adhered Sca1-positive cells. Furthermore, in bone marrow transplantation experiments, adhered Sca1-positive cells showed successful engraftment. We explored the role of Polycomb genes in the regulation of cell fate and found that self-renewing cells attached to osteoblasts had high Bmi-1 expression and low Mel-18 expression, while this expression was reversed in differentiating cells.

Conclusions: Our results suggest that hematopoietic stem cells self-renew when they remain in osteoblastic niches after cell division. Further, when stem cells leave the niches, they undergo differentiation.

Keywords: Hematopoietic stem cells (HSCs); osteoblasts; stem cell niche; stem cell self-renewal

Received: 16 March 2021; Accepted: 11 August 2021; Published: 11 October 2021.

doi: $10.21037 /$ sci-2021-019

View this article at: https://dx.doi.org/10.21037/sci-2021-019

\section{Introduction}

The self-renewal and the differentiation of hematopoietic stem cells (HSCs) are two distinct processes that depend on niche composition (1-3). Two types of HSC niches have been identified: osteoblastic niches (4-6) and vascular endothelial niches $(7,8)$. Extensive evidence has shown the importance of osteoblastic niches in self-renewal and differentiation. The spindle-shaped $\mathrm{N}$-cadherin ${ }^{+} \mathrm{CD} 45^{-}$ osteoblastic cells located on the bone surface are a key component of this type of niche and support HSCs through a specific adhesive interaction between $\mathrm{N}$-cadherin and $\beta$-catenin (5). Tie $2^{+}$HSCs localize to the endosteal surface 
of the bone marrow (7). Its ligand, angiopoietin-1, is mainly produced by osteoblasts. Angiopoietin-1 cells can also be detected from the bone surface and are co-expressed with osteocalcin, a marker of osteoblasts. Moreover, the expression of $\mathrm{N}$-cadherin in HSCs increases when the cells are cultured on feeder layers of OP9 stromal cells that are transfected with full-length angiopoietin-1, leading to the maintenance of self-renewal and protection of HSCs from stress factors. Calvi et al. (4) reported that osteoblastic cells with activated parathyroid hormone receptors increase the production of Notch ligand jagged 1, which leads to an increased number of HSCs. Furthermore, thrombopoietin produced by osteoblast administration transiently increases the quiescent population of HSCs (9), which suggests that the thrombopoietin/Mpl pathway is a component of the HSC osteoblastic niche. Although related to both osteoblastic and vascular endothelial niches, most $\mathrm{Lin}^{-} \mathrm{Sca}-$ $1^{+} \mathrm{c}-\mathrm{Kit}^{-}$(LSK) cells were found to be in contact with cells expressing high amounts of CXCL12 (10), called CXCL12abundant reticular cells.

Previous studies have reported the role of Polycomb group genes, including Bmi-1, Rae-28, and Mel-18 (11-14), in the self-renewal of HSCs. Polycomb genes are epigenetic regulators that play a key role in gene repression through chromatin modification (15). Bmi-1 expression is required for the generation of self-renewing HSCs (14), while an increase in Mel-18 expression promotes differentiation (11). Moreover, Bmi-1 and Mel-18 share the same structural motif, and we have previously reported that the ratio between Bmi-1 and Mel-18 expression determines whether the cell self-renews or progresses to differentiation (12).

In addition to the influence of intrinsic factors, we have previously reported the role of extrinsic factors, such as gravity in cell culture, in the differentiation of HSCs $(16,17)$. Therefore, we believe that other systems that are important for determining the fate of stem cells, such as the bone marrow microenvironment, are upstream of intrinsic factors.

Specific culturing methods for studying the mechanisms of self-renewal in vitro and in vivo have been previously reported. Hematopoietic cells can be maintained on bone marrow stromal cells for several months (18), and their colony-forming ability can be maintained during longterm survival (18-23). Thrombopoietin can maintain undifferentiated hematopoietic cells for a long period of time when co-cultured with stromal cells $(24,25)$. Several cell lines that maintain hematopoiesis have also been reported (26-29), making long-term culturing easier while allowing for in vitro regeneration. In contrast to maintaining undifferentiated HSCs, we aimed to analyze the regulatory mechanism of HSC self-renewal and hypothesized that HSC self-renewal would be affected by attachment to osteoblasts. We present the following article in accordance with the ARRIVE reporting checklist (available at https:// dx.doi.org/10.21037/sci-2021-019).

\section{Methods}

\section{Mice}

For this experiment, 5- to 8-week-old C57BL/6 mice were used. Ly5.1 mice were obtained from Sankyo Labo Service Corporation (Tokyo, Japan) and Ly5.2 mice are routinely used in our laboratory. All mice were bred and maintained in an animal facility at Hiroshima University. The light was maintained from 8:00 to 20:00, and the mice were fed a radiation-sterilized diet (CLEA Japan, Inc., Tokyo, Japan). This study was approved by the Animal Care and Use Committee of Hiroshima University (approval number 198 ), in compliance with institutional guidelines for the care and use of animals.

\section{Purification of murine bone marrow Sca1-positive cells}

Mice were sacrificed by cervical dislocation, and their femurs and tibias were removed. The bone marrow was flushed from the medullary cavities of murine bones using $\mathrm{Ca}^{2+}$ - or $\mathrm{Mg}^{2+}$-free phosphate-buffered saline. To purify hematopoietic progenitor/stem cells, the collected cells were labeled with anti-Sca1 microbeads and allophycocyaninconjugated anti-cKit from BD PharMingen (Franklin Lakes, NJ, USA; Catalog number 553356) and purified using a magnetically activated cell sorter system (Miltenyi Biotech, Auburn, CA, USA; Catalog number 130-091-176).

\section{Co-culture with hematopoietic cells and osteoblasts}

Briefly, Sca1-positive cells purified using magnetic beads were co-cultured with human osteoblasts. Human osteoblasts were used to prevent contamination of murine osteoblasts in the bone marrow. After $24 \mathrm{~h}$, the cell plate was turned upside down on a bigger plate, and the medium was changed after $24 \mathrm{~h}$. Through this procedure, cells that did not attach to the osteoblasts were removed. After $48 \mathrm{~h}$ ( $24 \mathrm{~h}$ for cell division experiments), the precipitated cells and the cells that were attached to osteoblasts 
Table 1 Primers used for quantitative real-time reverse transcriptase polymerase chain reaction

\begin{tabular}{lll}
\hline Gene (mouse) & Sense primer & Antisense primer \\
\hline Bmi-1 & 5'-TGT GTC CTG TGT GGA GGG TA-3' & 5'-TTT GTG AAC CTG GAC ATC ACA-3' \\
Mel-18 & 5'-CCC CAG CTA CCC ATC CTA CT-3' & 5'-GGA GCG CCA TTA ACA GTC AT-3' \\
Actb & 5'-CAT CCG TAA AGA CCT CTA TGC CAA C-3' & 5'-ATG GAG CCA CCG ATC CAC A-3' \\
\hline
\end{tabular}

were collected separately, and Sca1-positive cells were purified again using magnetic beads. The basic culture medium used was Dulbecco's modified Eagle's medium (Amersham Biosciences, Piscataway, NJ, USA). In addition, STEMPRO-34 nutrient supplement (Invitrogen, Carlsbad, CA; Catalog number 10641) and cytokines were added to this medium. Human Flt3-ligand (PeproTech, London, UK) and human thrombopoietin (Kirin Brewery, Tokyo, Japan) were added to each medium at a final concentration of $20 \mathrm{ng} / \mathrm{mL}$.

\section{Analysis of cell division using carboxyfluorescein succinimidyl ester (CFSE)}

Sca1-positive cells were labeled with CFSE to analyze cell division after culturing. Staining was performed according to the manufacturer's instructions (Molecular Probes, Eugene, OR, USA).

\section{Quantitative real-time reverse transcriptase ( $R T)$ polymerase chain reaction (PCR)}

To analyze the expression of $B m i-1$ and $M e l-18$ in each cell fraction, reverse transcription PCR was performed using ExScript RT and SYBR Premix Ex Taq (Takara Bio) according to the manufacturer's instructions. Real-time PCR was used for quantitative analysis of gene expression (Opticon; Bio-Rad Laboratories, Hercules, CA, USA) with specific primers (Table 1).

\section{Methylcellulose colony assay}

In vitro colony-forming cell activity was assessed using a methylcellulose colony assay. Bone marrow cells $(1,000$ cells per well) were cultured in methylcellulose medium containing various cytokines, such as recombinant stem cell factor, recombinant mouse interleukin-6, recombinant human interleukin-6, and recombinant human erythropoietin (Methocult GF M3434; StemCell Technologies, Vancouver, Canada; Catalog number 03434). Culture plates were incubated at $37^{\circ} \mathrm{C}$ for 7 days in a humidified atmosphere with $5 \% \mathrm{CO}_{2}$. Colonies were defined as a group of $>50$ cells. Erythroid, myeloid, and mixed erythroid-myeloid colonies were counted using an inverted microscope. A secondary colony-forming cell assay was performed by replating aliquots of the cells obtained by harvesting complete primary colonies. The secondary colonies were counted after an additional 7-day period of incubation.

\section{In vivo bone marrow transplantation assay}

We performed a transplantation experiment on the $\mathrm{F} 1$ hybrids of Ly5.1 and Ly5.2 mice. Two groups of at least nine mice were transplanted with either non-adhered Sca1-positive cells or adhered Sca1-positive cells. The donor-cultured Sca1positive cells $\left(2.5 \times 10^{2}\right)$ and competitor fresh marrow cells $\left(2 \times 10^{5}\right)$ were intravenously transplanted into the F1 recipients. Recipient mice were treated orally with busulfan (total dose of $180-200 \mathrm{mg} / \mathrm{kg}$ body weight over 5 days). Sixteen weeks after transplantation, peripheral blood samples were collected from the recipient mice. The two transplant cell populations were distinguished by staining the cells with phycoerythrin-conjugated anti-Ly5.1 and allophycocyaninconjugated anti-Ly5.2. All antibodies were purchased from Abcam (Cambridge, UK).

\section{Statistical analyses}

The Mann-Whitney $U$ test was performed using BellCurve for Excel statistical software (ver. 2.15; Social Survey Research Information, Tokyo, Japan). Values are presented as the mean \pm standard deviation.

\section{Results}

\section{Co-culture with hematopoietic cells and osteoblasts}

To confirm our hypothesis that HSCs self-renew when they adhere to osteoblasts and differentiate when they detach from osteoblasts (Figure 1A), murine Sca1-positive cells 

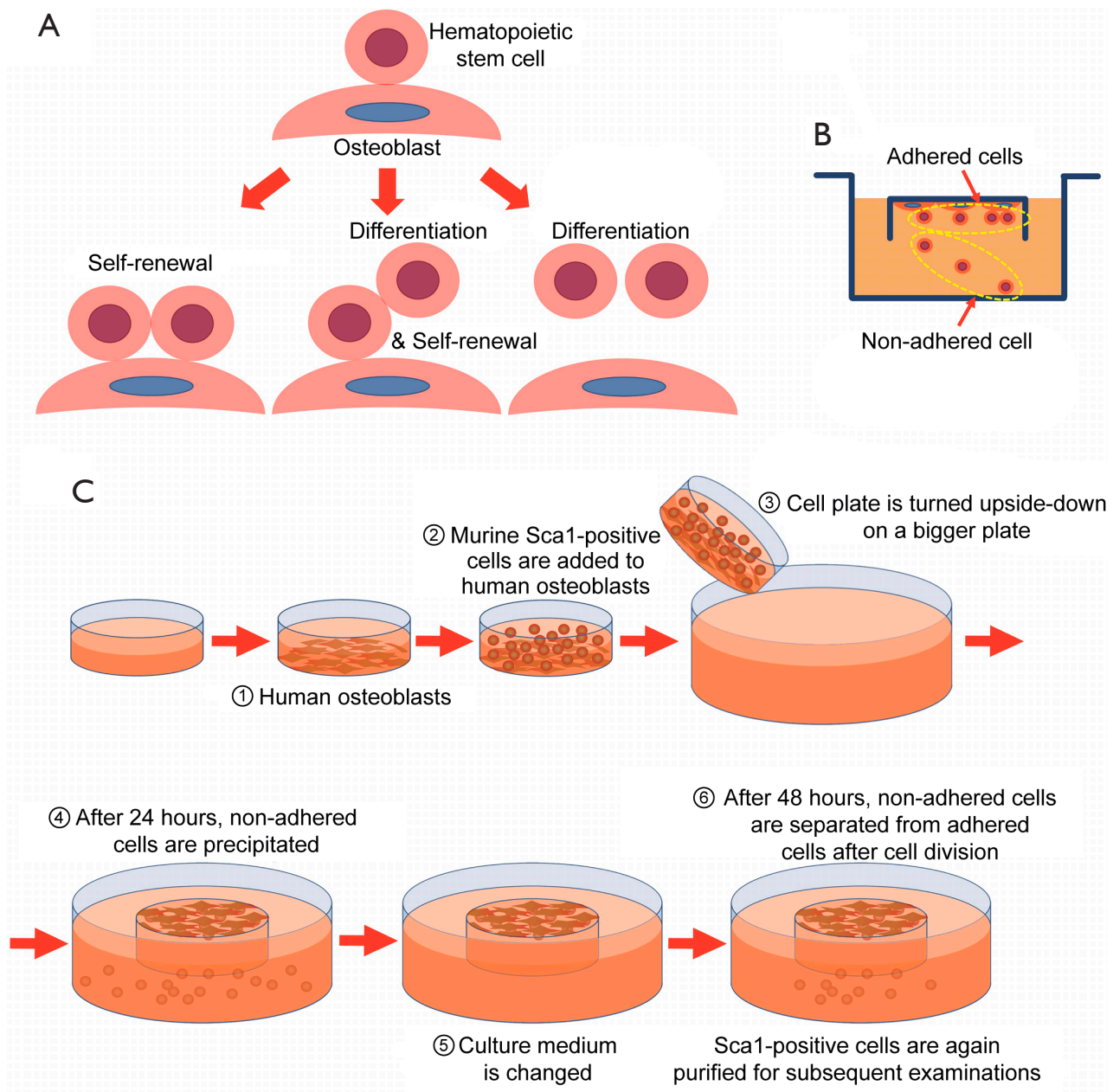

Figure 1 Co-culture with hematopoietic cells and osteoblasts. (A) Model of the hypothesis on hematopoietic stem cell self-renewal. (B) We designed an inverted culture system to separate cells adhered to osteoblasts from those detached from osteoblasts. (C) Culture procedure. Briefly, Sca1-positive cells are added to osteoblasts. Then, the cell plate is turned upside down on a bigger plate. After 24 h, non-adhered cells precipitate and the culture medium is changed. Sca1-positive cells that did not adhere to the osteoblasts within $24 \mathrm{~h}$ are removed. After $48 \mathrm{~h}$, non-adhered cells are separated from adhered cells after cell division.

were separated into an adhered cell fraction and a nonadhered cell fraction. For this, we designed an inverted culture system (Figure 1B) based on the fetal thymus organ culture method, which allowed for the collection of cells that had detached from osteoblasts. In addition, we used normal human osteoblasts to easily separate murine hematopoietic cells from osteoblasts. The culture procedure is illustrated in Figure 1C.

\section{Investigation of the cell division number of murine Sca1- positive cells}

The number of cell divisions was analyzed using only attached and precipitated Sca1-positive cells because floating Sca1-positive cells could be dead or weakened cells that had detached from osteoblasts. The murine Sca1positive cell fraction that was purified using magnetic beads had a purity of approximately $80-90 \%$ (Figure $2 A$ ). First, purified Sca1-positive cells were stained with CFSE and cultured on osteoblasts. Murine Sca1-positive cells were separated into adhered and non-adhered cell fractions, and the number of cell divisions was analyzed by flow cytometry. Almost all adhered Sca1-positive cells underwent 2-3 cell divisions after $48 \mathrm{~h}$ of culture, and only a few cells did not undergo cell division after $72 \mathrm{~h}$ of culture. Similarly, almost all non-adhered Sca1-positive cells underwent 2-3 cell 
A
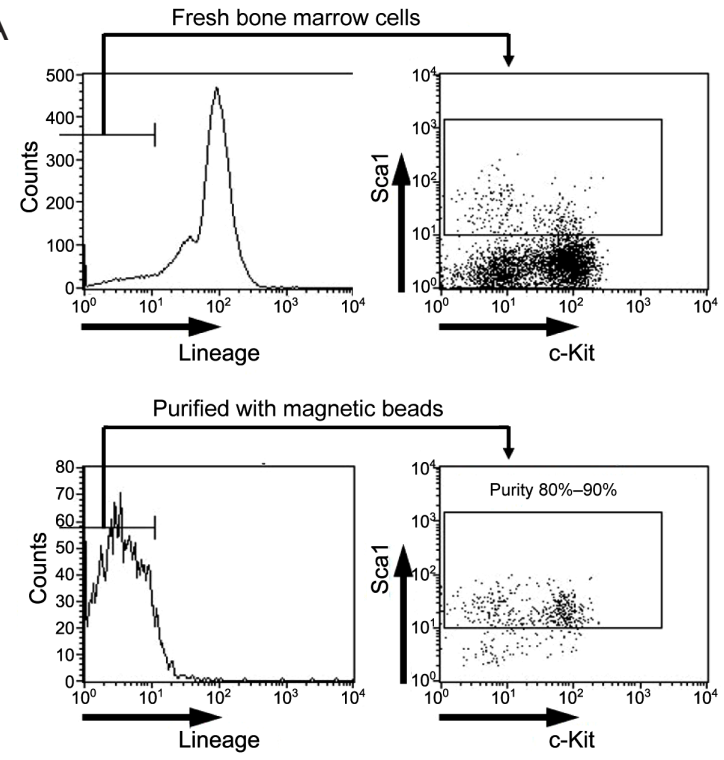

B

Before culture

Sca $1^{+}$cells

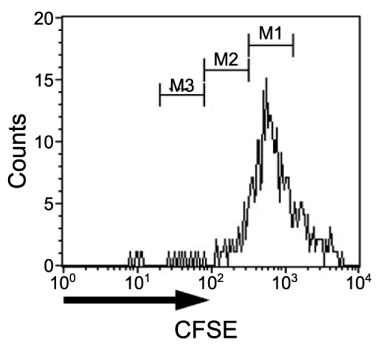

Number of cell divisions

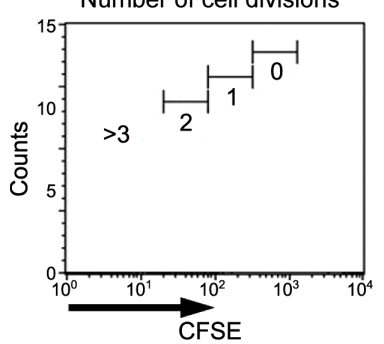

Adhered Sca1 ${ }^{+}$cells to osteoblasts
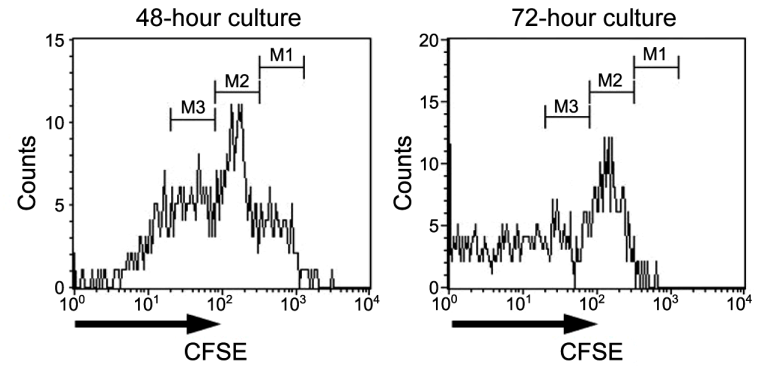

Non-adhered Sca1 ${ }^{+}$cells
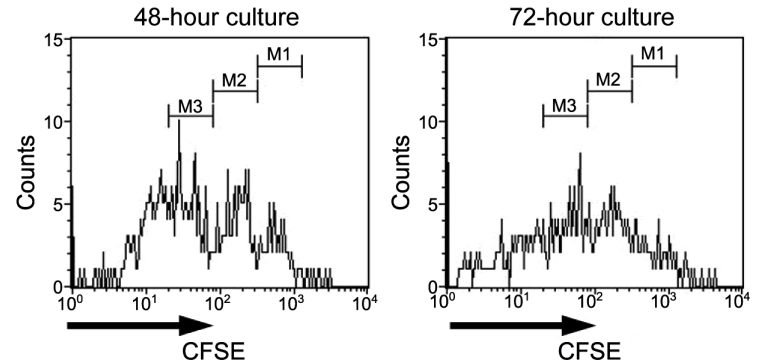

Figure 2 Investigation of murine Sca1-positive cells that underwent cell division. (A) Murine Sca1-positive cells purified using magnetic beads with a purity of approximately $80-90 \%$, as determined by flow cytometric analysis. (B) The fluorescence intensity before the culture of carboxyfluorescein succinimidyl ester-stained Sca1-positive cells is determined to represent cells that had not undergone cell division (0 times). The panels are representative data from eight experiments. CFSE, carboxyfluorescein succinimidyl ester.

divisions after $48 \mathrm{~h}$ of culture; however, there were more adhered cells than non-adhered cells that did not undergo cell division after $72 \mathrm{~h}$ of culture. Although the nondividing cells may have been detached from osteoblasts, they were fewer in number than non-adhered Sca1-positive cells (Figure 2B).

\section{Functional analysis of attached and precipitated Sca1-} positive cells in vitro

We examined secondary colony cells for primitive hematopoiesis (6-8). The type of colonies (e.g., granulocyte-macrophage colony-forming units and 

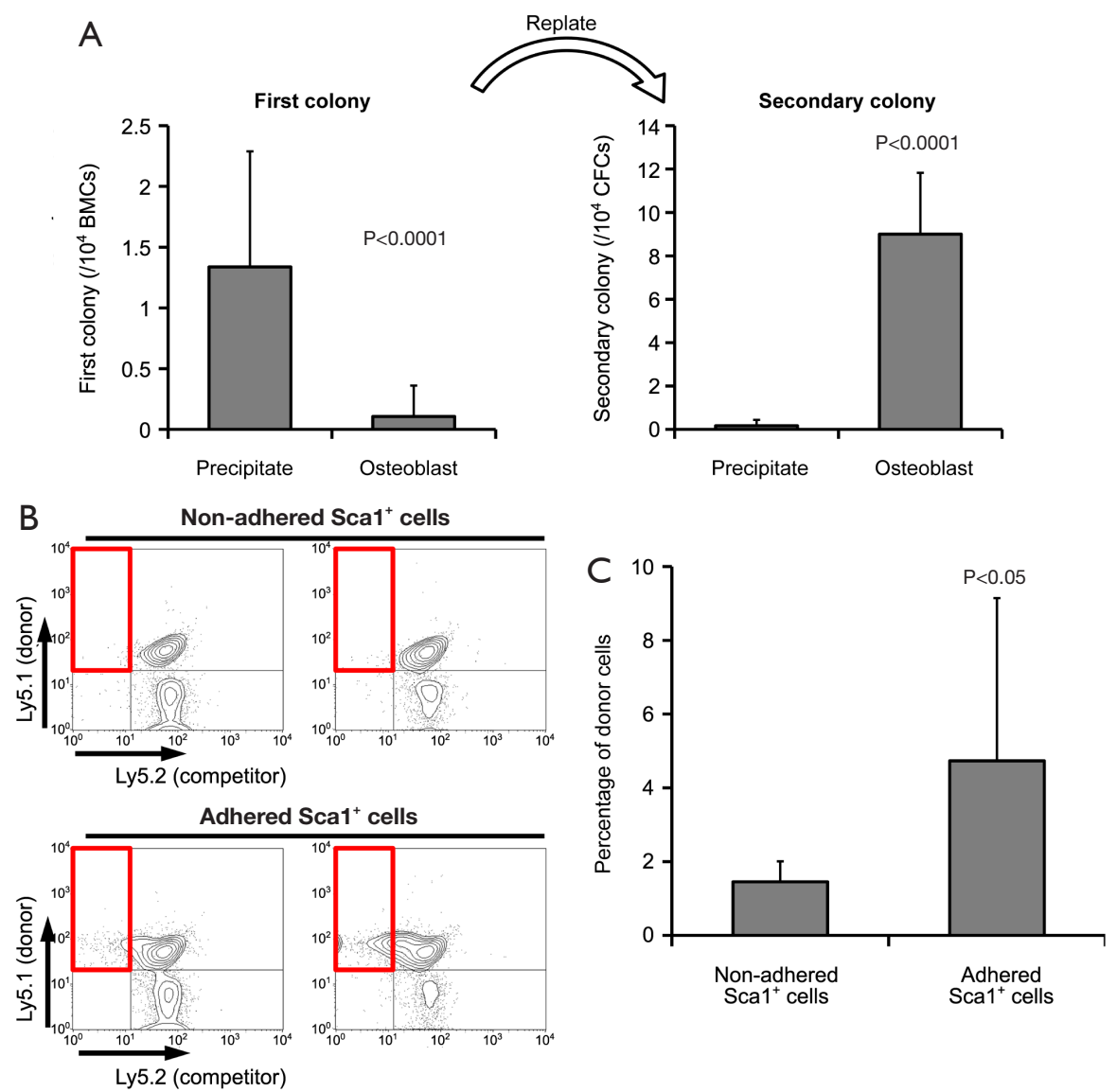

Figure 3 Functional analysis of Sca1-positive cells. (A) Secondary colony cells are examined for primitive hematopoiesis. (B) Representative profiles from at least nine independent experiments of peripheral blood cells after bone marrow transplantation, as determined by flow cytometric analysis. (C) The number of hematopoietic cells derived from attached Sca1-positive cells significantly increased 16 weeks after transplantation. Values are represented as mean \pm standard deviation of 24 assays (A) and at least nine transplanted mice per group (C). BMCs, bone marrow cells; CFCs, colony-forming cells.

erythroid burst-forming units) did not differ between the fractions. However, non-adhered Sca1-positive cells had a significantly greater number of first colonies, whereas adhered Sca1-positive cells had a significantly greater number of secondary colonies (Figure $3 A$ ). These results suggest that the fraction of adhered Sca1-positive cells included more stem cells and that the fraction of nonadhered Sca1-positive cells included more progenitor cells.

\section{Functional analysis of adbered and precipitated Sca1- positive cells in vivo}

Sca1-positive cells used for this experiment were collected from the bone marrow of Ly5.1 mice. We performed a transplantation experiment in which the recipient mice were F1 hybrids of Ly5.1 and Ly5.2 mice. We used Ly5.1 cells as competitors to ensure that the mice did not die after transplantation due to graft failure. Representative profiles of flow cytometric analysis are shown in Figure $3 B$. There were significantly more hematopoietic cells derived from adhered Sca-1-positive cells in the peripheral blood 16 weeks after transplantation than those derived from nonadhered Sca-1-positive cells (Figure 3C).

\section{Expression of Polycomb group genes in adbered and precipitated Sca1-positive cells}

We analyzed two Polycomb group genes (Bmi-1 and Mel-18) that are involved in HSC self-renewal, as reported previously (11-13). The expression of Bmi-1, which is 
essential for HSCs, was significantly higher in adhered Sca1-positive cells than in precipitated Sca1-positive cells $(\mathrm{P}=0.3857)$. In contrast, the expression of $\mathrm{Mel}-18$ was significantly lower in adhered Sca1-positive cells than in precipitated Sca1-positive cells ( $\mathrm{P}=0.0160$; Figure 4).
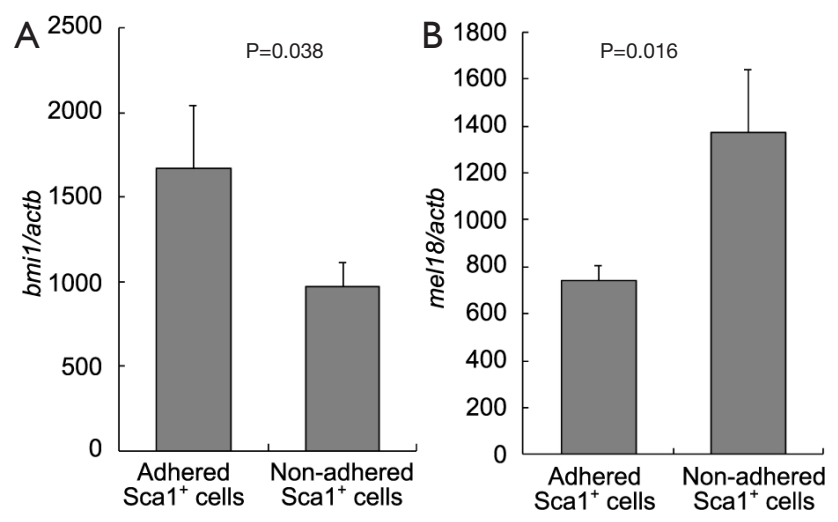

Figure 4 Expression of Polycomb genes in each fraction of Sca1positive cells. The expression of Bmi-1 and $M e l-18$ is normalized to the $A c t b$ housekeeping gene. Values are represented as mean \pm standard deviation of three experiments.

\section{Discussion}

Our results suggest that when HSCs remain in osteoblastic niches after cell division, they self-renew and that when stem cells leave the niches, they undergo differentiation. To graphically represent this hypothesis, we compared HSCs to takoyaki balls (a popular food in Japan) and the niches to the wells of a takoyaki pan (Figure 5). The number of HSCs was regulated so that the cells would not be depleted in the bone marrow. In the bone marrow transplantation experiment, when the transfused HSCs entered vacant niches, they selfrenewed and then occupied other empty niches (30). In other words, HSCs are not depleted by undergoing 1-2 cell divisions after transplantation. The niches participate not only in the control of HSCs but also in the engraftment of transfused HSCs $(1,2,31)$. Based on this concept, adjusting the number of osteoblasts and HSCs would confirm the hypothesis that HSCs begin to differentiate after they fill vacant niches. This may determine whether the self-renewal of HSCs follows the stochastic model, the instructive model, or both.

The expression of Bmi-1 was higher in osteoblast-adhered Sca1-positive cells than in non-adhered Sca1-positive cells.

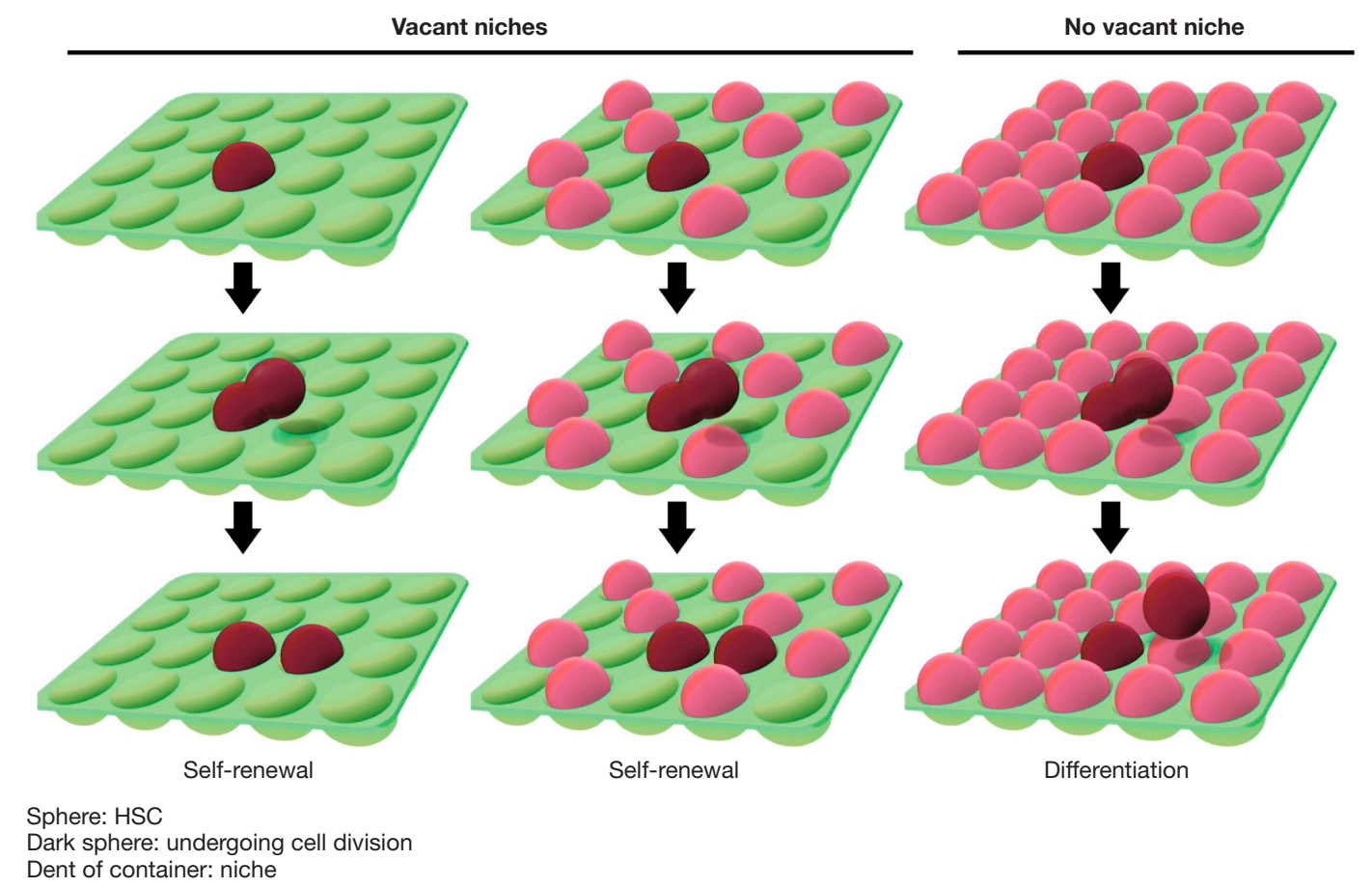

Figure 5 Model of HSC self-renewal: the "takoyaki hypothesis". This hypothesis can be easily understood by comparing HSCs to takoyaki balls and the niches to the wells of a takoyaki pan. HSCs self-renew when they remain in osteoblastic niches after cell division and differentiate when they leave the niches. HSC, hematopoietic stem cell. 
However, the expression of Mel-18 was lower in osteoblastadhered Sca1-positive cells. Therefore, it seems that Polycomb genes do not directly regulate self-renewal, suggesting that adhesion to the osteoblast niche may occur upstream of Polycomb genes. Further studies are needed to explore the exact mechanism of Polycomb gene control.

There have been many reports concerning the molecular mechanism of adhesion between osteoblastic niches and HSCs. When mesenchymal stem cells differentiate into osteoblasts, they lose their ability to promote HSC self-renewal (32). In this study, by transfecting various genes into osteoblasts, we were able to investigate whether these molecules were related not only to the maintenance of HSCs but also to the ability of the cells to self-renew. In addition, various internal factors associated with the self-renewal of HSCs, such as Bmi-1, have been reported, highlighting their importance in stem cell biology.

This pilot study sheds light on the mechanisms underlying the osteogenic microenvironment. We hope that this study will promote future investigations on the mechanism of HSC self-renewal and differentiation and that it will be useful for clinical HSC transplantation. Moreover, the co-culture method we developed can be used for further investigation of the mechanism of HSC selfrenewal.

\section{Conclusions}

Our results provide novel insights into the important role played by the osteogenic microenvironment in the fate of HSCs. We showed that HSCs that remain in osteoblastic niches self-renew after cell division, whereas those that leave these niches undergo differentiation.

\section{Acknowledgments}

We would like to thank Prof. Yoshihiro Takihara (Department of Stem Cell Biology, Research Institute for Radiation Biology and Medicine, Hiroshima University) for providing guidance regarding bone marrow transplantation. We thank the Analysis Center of Life Science, Hiroshima University, for allowing us to use their facilities. Editorial support, including medical writing, high-resolution image creation, collating author comments, copy-editing, factchecking, and referencing, was provided by Editage, Cactus Communications.

Funding: This work was supported by a grant from the
Association for the Advancement of Medicine of the Tsuchiya Foundation in 2007.

\section{Footnote}

Reporting Checklist: The authors have completed the ARRIVE reporting checklist. Available at https://dx.doi. org/10.21037/sci-2021-019

Conflicts of Interest: All authors have completed the ICMJE uniform disclosure form (available at https://dx.doi. org/10.21037/sci-2021-019). The authors have no conflicts of interest to declare.

Ethical Statement: The authors are accountable for all aspects of the work in ensuring that questions related to the accuracy or integrity of any part of the work are appropriately investigated and resolved. Experiments were performed under a project license (approval number 198) granted by the Animal Care and Use committee board of Hiroshima University in compliance with institutional guidelines for the care and use of animals.

Open Access Statement: This is an Open Access article distributed in accordance with the Creative Commons Attribution-NonCommercial-NoDerivs 4.0 International License (CC BY-NC-ND 4.0), which permits the noncommercial replication and distribution of the article with the strict proviso that no changes or edits are made and the original work is properly cited (including links to both the formal publication through the relevant DOI and the license). See: https://creativecommons.org/licenses/by-nc$\mathrm{nd} / 4.0 /$.

\section{References}

1. Scadden DT. The stem-cell niche as an entity of action. Nature 2006;441:1075-9.

2. Morrison SJ, Spradling AC. Stem cells and niches: mechanisms that promote stem cell maintenance throughout life. Cell 2008;132:598-611.

3. Cordeiro Gomes A, Hara T, Lim VY, et al. Hematopoietic Stem Cell Niches Produce Lineage-Instructive Signals to Control Multipotent Progenitor Differentiation. Immunity 2016;45:1219-31.

4. Calvi LM, Adams GB, Weibrecht KW, et al. Osteoblastic cells regulate the haematopoietic stem cell niche. Nature 2003;425:841-6. 
5. Zhang J, Niu C, Ye L, et al. Identification of the haematopoietic stem cell niche and control of the niche size. Nature 2003;425:836-41.

6. Arai F, Hirao A, Ohmura M, et al. Tie2/angiopoietin-1 signaling regulates hematopoietic stem cell quiescence in the bone marrow niche. Cell 2004;118:149-61.

7. Kiel MJ, Yilmaz OH, Iwashita T, et al. SLAM family receptors distinguish hematopoietic stem and progenitor cells and reveal endothelial niches for stem cells. Cell 2005;121:1109-21.

8. Huang X, Li C, Zhu B, et al. Co-cultured hBMSCs and HUVECs on human bio-derived bone scaffolds provide support for the long-term ex vivo culture of HSC/HPCs. J Biomed Mater Res A 2016;104:1221-30.

9. Yoshihara H, Arai F, Hosokawa K, et al. Thrombopoietin/ MPL signaling regulates hematopoietic stem cell quiescence and interaction with the osteoblastic niche. Cell Stem Cell 2007;1:685-97.

10. Sugiyama T, Kohara H, Noda M, et al. Maintenance of the hematopoietic stem cell pool by CXCL12-CXCR4 chemokine signaling in bone marrow stromal cell niches. Immunity 2006;25:977-88.

11. Kajiume T, Ninomiya $Y$, Ishihara H, et al. Polycomb group gene mel-18 modulates the self-renewal activity and cell cycle status of hematopoietic stem cells. Exp Hematol 2004;32:571-8.

12. Kajiume T, Ohno N, Sera Y, et al. Reciprocal expression of Bmil and Mel-18 is associated with functioning of primitive hematopoietic cells. Exp Hematol 2009;37:857-866.e2.

13. Kajiume T, Sera Y, Kawahara Y, et al. Regulation of hematopoietic stem cells using protein transduction domain-fused Polycomb. Exp Hematol 2012;40:751760.e1.

14. Park IK, Qian D, Kiel M, et al. Bmi-1 is required for maintenance of adult self-renewing haematopoietic stem cells. Nature 2003;423:302-5.

15. Iwama A. Polycomb repressive complexes in hematological malignancies. Blood 2017;130:23-9.

16. Kajiume T, Yuge L, Kawahara Y, et al. Floating culture promotes the maintenance of hematopoietic stem cells. FEBS Lett 2007;581:4645-50.

17. Kawahara Y, Manabe T, Matsumoto M, et al. LIF-free embryonic stem cell culture in simulated microgravity. PLoS One 2009; 4:e6343.

18. Dexter TM, Allen TD, Lajtha LG. Conditions controlling the proliferation of haemopoietic stem cells in vitro. J Cell Physiol 1977;91:335-44.
19. Toogood IR, Dexter TM, Allen TD, et al. The development of a liquid culture system for the growth of human bone marrow. Leuk Res 1980;4:449-61.

20. Moore MA, Sheridan AP, Allen TD, et al. Prolonged hematopoiesis in a primate bone marrow culture system: characteristics of stem cell production and the hematopoietic microenvironment. Blood 1979;54:775-93.

21. Wilkinson AC, Ishida R, Kikuchi M, et al. Long-term ex vivo haematopoietic-stem-cell expansion allows nonconditioned transplantation.

Nature 2019;571:117-21.

22. Bai T, Li J, Sinclair A, et al. Expansion of primitive human hematopoietic stem cells by culture in a zwitterionic hydrogel. Nat Med 2019;25:1566-75.

23. Ieyasu A, Ishida R, Kimura T, et al. An All-Recombinant Protein-Based Culture System Specifically Identifies Hematopoietic Stem Cell Maintenance Factors. Stem Cell Reports 2017;8:500-8.

24. Yagi M, Ritchie KA, Sitnicka E, et al. Sustained ex vivo expansion of hematopoietic stem cells mediated by thrombopoietin. Proc Natl Acad Sci U S A 1999;96:8126-31.

25. Decker M, Leslie J, Liu Q, et al. Hepatic thrombopoietin is required for bone marrow hematopoietic stem cell maintenance. Science 2018;360:106-10.

26. Kodama $H$, Nose $M$, Niida $S$, et al. Involvement of the c-kit receptor in the adhesion of hematopoietic stem cells to stromal cells. Exp Hematol 1994;22:979-84.

27. Kodama H, Nose M, Yamaguchi $Y$, et al. In vitro proliferation of primitive hemopoietic stem cells supported by stromal cells: evidence for the presence of a mechanism(s) other than that involving c-kit receptor and its ligand. J Exp Med 1992;176:351-61.

28. Nishikawa S, Nakasato M, Takakura N, et al. Stromal cell-dependent bone marrow culture with a nearly protein-free defined medium. Immunol Lett 1994;40:163-9.

29. Klamer SE, Dorland YL, Kleijer M, et al. TGFBI Expressed by Bone Marrow Niche Cells and Hematopoietic Stem and Progenitor Cells Regulates Hematopoiesis. Stem Cells Dev 2018;27:1494-506.

30. Taya Y, Ota Y, Wilkinson AC, et al. Depleting dietary valine permits nonmyeloablative mouse hematopoietic stem cell transplantation. Science 2016;354:1152-5.

31. Crane GM, Jeffery E, Morrison SJ. Adult haematopoietic stem cell niches. Nat Rev Immunol 2017;17:573-90. 
32. He Q, Scott Swindle C, Wan C, et al. Enhanced Hematopoietic Stem Cell Self-Renewal-Promoting Ability of Clonal Primary Mesenchymal Stromal/Stem

doi: $10.21037 /$ sci-2021-019

Cite this article as: Kajiume T, Kawahara Y, Yuge L, Kobayashi M. Osteoblastic adherence regulates hematopoietic stem cell self-renewal and differentiation: a conceptional in vitro and in vivo study. Stem Cell Investig 2021;8:21. cells Versus Their Osteogenic Progeny. Stem Cells 2017;35:473-84. 